\title{
132 柔軟な弾性表面を持つ円筒周りの流れ場の可視化
} 一渦対の放出と後流の速度場および抗力の関係一

\author{
関西大院 中田 雅子 ${ }^{\bigcirc}$ 、関西大工 大場 謙吉
}

\author{
Visualization of Flow Field around Elasto-Flexible Cylinder \\ - Relationship between Emission of Vortex Pair, \\ Velocity Field in Wake and Drag Force- \\ Masako NAKATA $^{*}$ and Kenkichi OHBA ${ }^{* *}$
}

The purpose of this study is to clarify the mechanism of decreasing the drag in natural swimming of fish, whale and dolphin. A cylinder which has Elasto-flexible surface simplified marine creature was placed in a water tunnel, and using Laser Light Sheet method to visualize flow field around the model, vortex pair shedding period from the model, deformation of its cross-sectional form and hydrodynamical drag of the model were simultaneously measured. As a result, the following were found: the rigid front flexible rear cylinder model has showed about $20 \%$ higher St number than rigid cylinder model. The local deformation of the surface changed local flow pattern and wake due to some interaction between flexible surface and vortex. Time variation of the drag of the Rigid Front Flexible Rear Cylinder (RFFRC) became smaller than rigid one.

\section{1.はしめに}

魚鯨類の遊泳中における抵抗がかなり小さいとはよく知られているが、その抵抗軽減 の機構は生体特有の様々な要因が複雑に絡み合っているため、解明されているとは言い難 (1)。しかし、この機構を解明することは、流体工学の分野で非常に有意義なことと考え られる。そこで本研究では魚鯨類、特にイル力は弾性表皮の微小振動によって抵抗を軽減 させていること帛に着目し、形状を簡略化した柔軟な弾性表面を持つ円筒周りの流れ場を レーザーライトシート法により可視化することによって渦の放出や後流の様子についての 観察と計測を行い、抗力についても測定を行った。

\section{2. 実験装置および方法}

本実験に用いた実験装置の概略をFig.1に示す。実験には、小型回流水槽を用い、密閉水 路にして一様な流れ場を発生させ、測定流路内に流れに対して垂直に円筒モデルを設置し た。測定流路下部よりアルゴンレーザーによるレーザーライトシート光を入射することに よって流れ場を可視化した。混入したトレーサはアルミナ被膜を施した平均粒径約 $290 \mu \mathrm{m}$ のポリエチレン粒子である。また流れ場の様子の記録は測定部側方の高速ビデオ カメラによって行い、得られたビデオ画像より渦対の放出周期を測定し、弾性壁を持つも のに関しては表面の挙動と流れ場の様子について観測を行った。抗力の測定には 3 分力検

* Graduate School of Kansai University, 3-3-35, Yamate-cho, Suita, Osaka

** Faculty of Engineering, Kansai University 


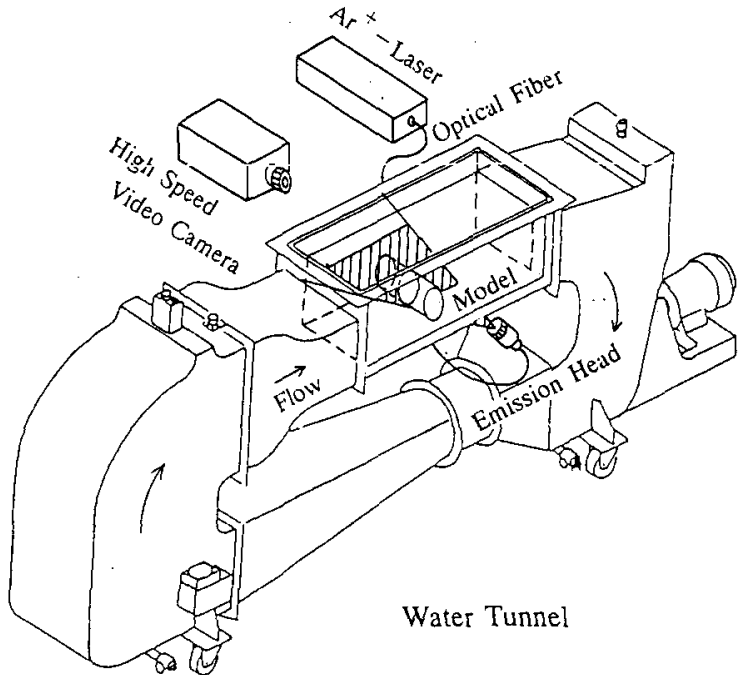

Fig.1 Outline of experimental apparatus

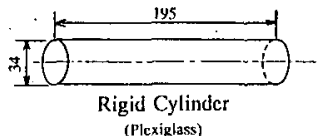

(Plexiglass)

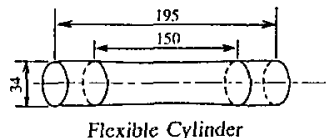

Flcxible Cylinder

(Natural Rubber $1=1.0 \mathrm{~mm}$; Latex Rubter $1=1.03 \mathrm{~mm}$ )

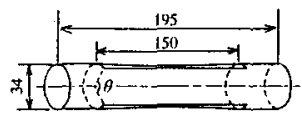

Rigid Front Flcxible Rear Cylinder (Plexiglass-Lalex Rublecr)

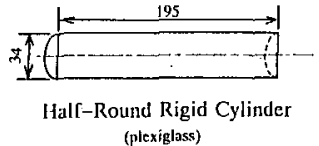

Fig.2 Models

出器を用いた。Fig.2にモデルとして使用した円筒を示す。モデルとしては剛体円筒（Rigid Cylinder）、柔軟弾性円筒（Flexible Cylinder）、前剛後柔の複合円筒（Rigid Front Flexible Rear Cylinder; 以下RFFRC）、剛体半円筒（Half-Round Rigid Cylinder）を用いた。

\section{3. 実験結果および考察}

3-1 壁面の柔軟性が渦の放出に及ぼす影響Ｆig.3に断面形状や壁面の柔軟性が洞対の 放出周波数に及ぼす影響を示した。壁面が柔軟なモデルのうち、柔軟弾性円筒は流れに よってたわみ、Fig.4に示すように断面形状が半円に近くなるため剥離点屯エッジ付近に移 動し、渦の放出周波数も剛体半円筒の測定結果に近い値か得られた。しかし、さらに流速 が速くなると渦励振し始め、ばらつきの多い結果となった。一方、RFFRCは流れによっ てたわむことがないため断面形状が著しく変わることはなく、それによって後面のゴム膜 の振動が顕著に現れ、渦の放出とともに 局所的に変形し、結果的にFig.3中に見ら れるように放出周波数が $20 \%$ 程度上昇し た。これは、RFFRCのモデル全てに見ら れる傾向ではなく、角度を変えたモデル の中では剥離点近傍の壁面が柔軟に動き

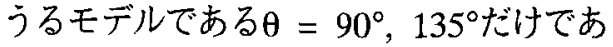
り、また、容積率を変えた実験では、容 積率90\%のモデルが放出周波数を高める 傾向にあった。以上のことから、剥離点 近傍の壁面が柔軟に流れ場に対応できる ことが渦の放出を早めることに大きく関 与していると考えられる。

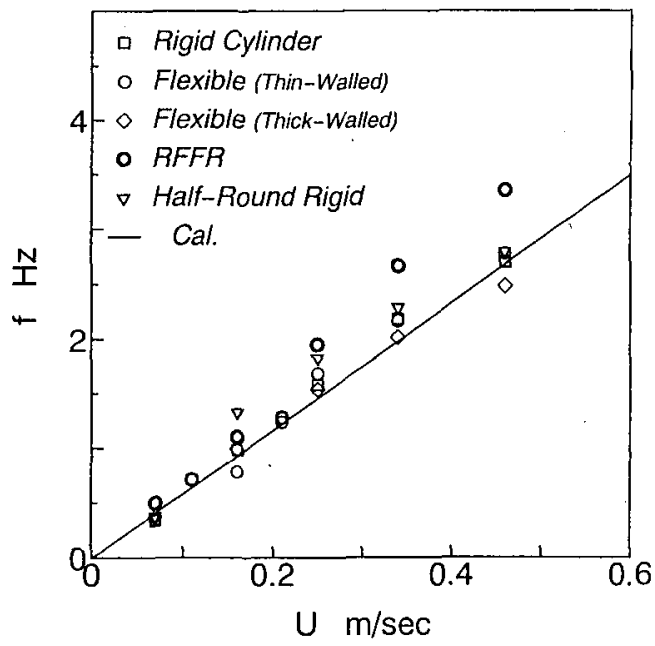

Fig.3 Effect of flexibility for vortices shedding 


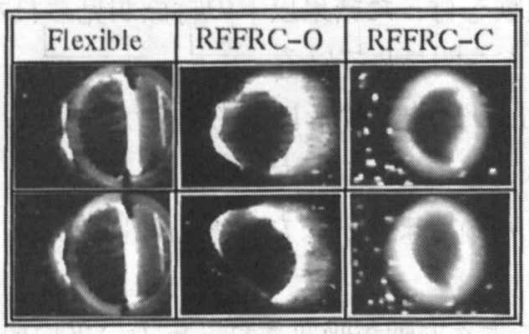

Fig.4 Cross section of the flexible models (a)

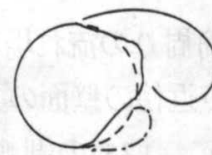

(d)

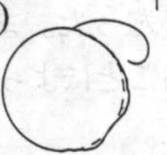

$\uparrow$ (b)

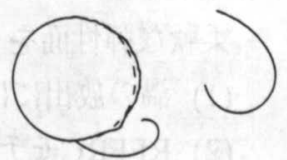

(c)

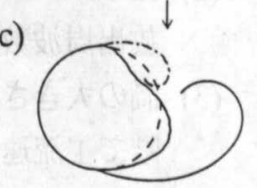

Fig.5 Mechanism of vortex shedding

3-2 柔軟な壁面と渦の放出メカニズム 剥離点近傍や円筒後面の変形が渦の放出メカ ニズムにどの様に影響を与えているのかについて、可視化画像をもとに観察し、スケッチ した結果をFig.5に示す。Fig.5は渦の放出周波数がきわめて特徵的に変化したRFFRC$90^{\circ}$ (開放型) モデルの放出メカニズムを示している。

(a)では、背圧の低下に伴って渦の発生方向の後面が引き付けられふくらむのに伴い、ゴ ムの弾性変形によって反対側にはへこみが生じる。そのへこみ動作につられて流れが吸い 込まれ、新しい渦を誘起する。そして、(b)吸い込みによって生じた渦が普通の剥離により 生じる巻き込みによって成長する。(c) $\rightarrow(d)$ は (a) $\rightarrow(b)$ の過程の渦発生場所が反対の場合で あり、以上(a)〜(d)のくり返しによって渦が発生していた。この“吸い込み”が加わるこ とで渦の発生が剛体円筒のそれに比べ早くなっていると考えられ、これが渦対の放出周波 数を高めた原因と考えられる。

3-3 柔軟な壁面が下流領域に及ぼす影響 Fig.6に剛体円筒とRFFRC-90の後流の可視 化写真と、可視化画像より測定した後流の流速分布を示す。図に見られるように、 RFFRCの後流は剛体円筒のものに比べて幅が狭く、また渦の大きさも小さいことが観測 された。ここで、各モデルの渦の形成領域長さについて測定した結果をFig.7に示す。Fig. 7より、RFFRC (-90、-135) の測定結果は他のモデルの結果がほぼ一定值をとっている のに対し、流速が速くなるにつれて渦形成長さが減少する傾向が見られた。このことは渦 が早い段階で渦度の供給を断たれていることを示し、また、それによって渦の大きさも小 さいまま放出されると推測される。また、Fig.6の流速分布からは、RFFRCの後流の流速 は距離の短い段階で主流速度に近つくことが明らかになった。これは、渦の大きさが小さ いため後流に及ぼす影響も小さくなったと考えられる。以上のことより、剥離点近傍の壁 面が柔軟に動きうることは、周囲の流体に及ぼす影響を縮小していることが推測される。

3-4 抗力と渦の放出の関係 後流の流速分布から運動量損失を求めることで剛体円筒 と同じようにRFFRCも抗力を計算することが可能なら、Fig.6より明らかにRFFRCは抗力 を減少させるモデルであると考えられる。そこで、実際に抗力を 3 分力検出器を用いて測 定した。Fig.8にその測定結果を示す。図より、抗力の平均値そのものについてはほとんど 違いは見られないが、抗力の渦の放出に伴う時間変動の幅はかなり小さくなった。このこ とから、モデル後面の振動が渦の放出による影響を吸収していると推測される。 


\section{4. まとめ}

柔軟な弾性面をもつ円筒周りの流れ場について実験を行った結果以下の特徴が見られた。

(1) 渦の放出には剥離点近傍の壁面の柔軟性が大きく関与している。

(2) RFFRCモデル(-90、-135)の剥離渦は、後面の柔軟な変形により放出が早められ、 放出周波数は約 $20 \%$ 高くなった。また、大きさも小さくなった。

(3) 渦の大きさが小さくなることによって後流の幅が狭まり、また流速も距離も短い段 階で主流速度に近ついた。

(4) RFFRCの後面の柔軟な変形によって剥離渦による振動が吸収され、抗力の平均値に 減少は見られないが、時間変動幅は小さくなった。

\section{5. 参考文献}

1) J. Lighthill; Mathematical Biofluiddynamics,

\section{SIAM}

2) 谷一郎; 科学; Vol.34 No.9, p.471-476, 1964
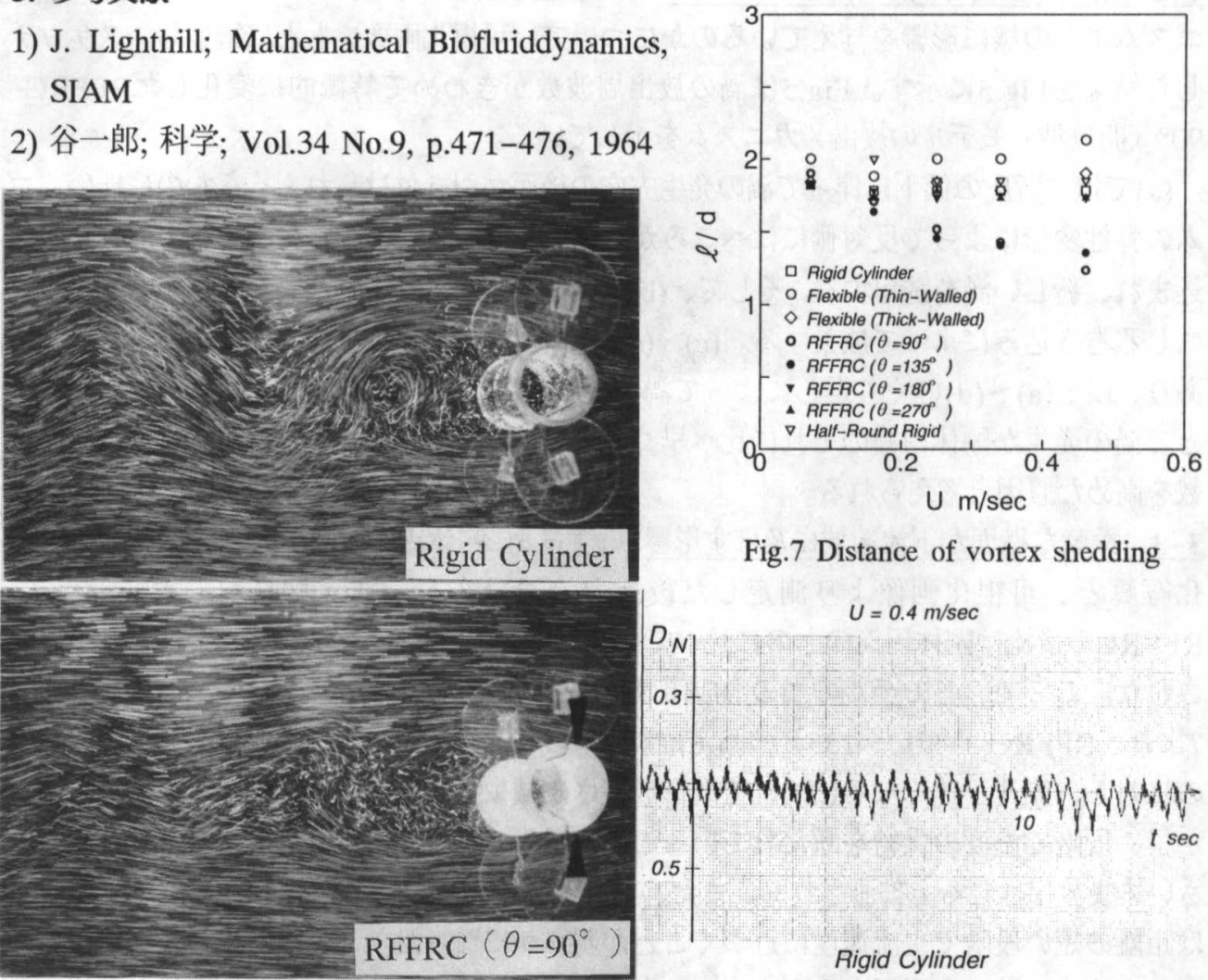
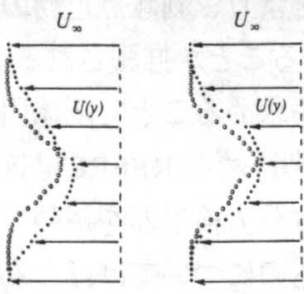

- Rigid

- RFFR

Fig.6 Visualized and measured wake velocity

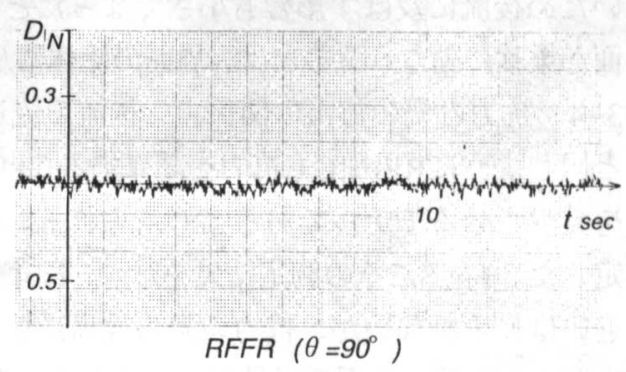

Fig.8 Time varying of the drag 